\title{
A Study on the Flexural Performance of UHPC Precast Deck-Joint Interface by the Exposure of Steel Fiber
}

\author{
Kilje Jung, Sung Yong Park, Sung Tae Kim, Byung-Suk Kim, Keunhee Cho* \\ Structural Engineering Research Division, SOC Research Institute, Korea Institute of Civil Engineering and \\ Building Technology, Goyang-Si, Korea \\ Email: kjjung01@outlook.com, sypark@kict.re.kr, esper009@kict.re.kr, bskim@kict.re.kr, ${ }^{*}$ kcho@kict.re.kr
}

Received 27 September 2014; revised 22 October 2014; accepted 16 November 2014

Copyright @ 2014 by authors and Scientific Research Publishing Inc.

This work is licensed under the Creative Commons Attribution International License (CC BY). http://creativecommons.org/licenses/by/4.0/

(c) (i) Open Access

\section{Abstract}

As a solution against the serviceability problem caused by the cracks occurring at the UHPC precast deck-joint interface, this study proposes a method exposing the steel fiber at the interface and evaluates the corresponding flexural performance of the lap spliced construction joint. After having slowed down the strength development of the concrete placed in the joint of the precast deck by means of a curing retardant, the concrete at the interface is crushed so as to expose the steel fibers and the change in the flexural performance is observed experimentally according to the exposure of the steel fibers. The results show that, even if the ultimate strength and stiffness of the UHPC precast deck including the joint are mostly determined by the arrangement details of the rebar lap splice, the exposure of the steel fibers can secure stable ductile behavior and reduce the width of the cracks generated at the precast deck-joint interface under service load.

\section{Keywords}

Ultra-High Performance Concrete, Precast Deck System, Steel Fiber Exposure, Lap-Spliced Connection, 4-Point Bending Test

\section{Introduction}

Ultra-High Performance Concrete (UHPC) is the latest concrete featured by an ultra-high strength larger than $150 \mathrm{MPa}$ and high toughness with a tensile strength higher than $5 \mathrm{MPa}$. UHPC is a promising material expected to find extensive exploitation in the construction market. With the ongoing research on innovative design and

\footnotetext{
"Corresponding author.
}

How to cite this paper: Jung, K., Park, S.Y., Kim, S.T., Kim, B.-S. and Cho, K. (2014) A Study on the Flexural Performance of UHPC Precast Deck-Joint Interface by the Exposure of Steel Fiber. Engineering, 6, 1000-1006. 
construction overcoming the limitations encountered in normal concrete structures, UHPC, which started to be applied in small-scale pedestrian bridges and as building material, is today exploited in large-scale civil structures like road bridges and railway bridges [1] [2].

Most of the structures using UHPC are erected by precast for quality control purpose. Accordingly, studies were carried out on the connections between the precast segments. Especially, studies were performed to simplify the sectional details and minimize the size of the connection in the precast deck using the high compressive strength and bond strength of UHPC. Graybeal and Swenty undertook tests for the evaluation of the performance of the precast deck joints considering the sectional details as test variables [3]. Hwang et al. proposed a unidirectional ribbed section with transverse prestress and conducted design optimization of the section [4]. The Korea Institute of Civil Engineering and Building Technology (KICT) conducted performance evaluation tests on precast deck connections subjected to positive moments in order to develop UHPC precast decks for cablestayed bridges. The considered test variables were the size of the connection and the lap-spliced length [5] [6]. According to the results of the research led at KICT, the lap-spliced connection satisfied the ultimate strength and allowable deflection criteria under service load recommended by the Korea Highway Bridge Design Code [7] but failed partially in satisfying the allowable crack width under service load prescribed in the Concrete Design Code and Commentary of the Korea Concrete Institute [8]. Consequently, supplementary experimental verification tests are still required for the applicability of the UHPC precast deck.

This study intends to evaluate the width control effect of the cracks generated in the connection by the exposure of the steel fiber contained in the contact interface between the joint and precast deck in a will to secure the serviceability of the UHPC precast deck with joint. The exposure of the steel fibers was achieved by crushing the connection concrete of which strength development was delayed by using a curing retardant. The size of the connection, the rebar spacing and bond length were determined based upon the results of a previous study [5]. The change in the flexural performance of the connection is evaluated according to the exposure of the steel fiber.

\section{Description of Specimens}

\subsection{Composition of Specimens}

Table 1 describes the characteristics of the specimens for the flexural performance test of the connection according to the exposure of steel fiber. The details of each specimen are illustrated in Figure 1. All the test members present identical dimensions and the sectional details are decided with respect to predetermined test variables that are the eventual rebar arrangement, the eventual presence of joint, and the eventual exposure of steel fiber. Even if the arrangement of reinforcement is indispensable to satisfy the structural performances prescribed by the design specifications of the UHPC precast deck, a non-reinforced specimen is considered to evaluate the extent of the increase in the flexural performance according to the steel fiber exposure. The rebar details of the reinforced specimens are determined based upon previous studies related to the static behavior of lap-spliced cast-in-place connection applying UHPC [5] [6]. The length of the connection is set to $200 \mathrm{~mm}$ and the lap-spliced length to $150 \mathrm{~mm}$ based on the findings of a research stating that these values achieve very similar load-deflection curves including the ultimate strength in the case of a 150-mm thick deck lap-spliced by 19mm rebar.

Table 1. Description of test members.

\begin{tabular}{cccccc}
\multirow{2}{*}{ Designation of specimen } & \multicolumn{2}{c}{ Tensile rebar } & Connection & Steel fiber exposure & $\begin{array}{c}\text { Number of } \\
\text { specimens }\end{array}$ \\
\cline { 2 - 3 } RN-CU & - & - & Placed concurrently & - & 2 \\
RN-CSF & - & - & Placed separately & Exposed & 2 \\
RS-CU & 19 & 150 & Placed separately & - & 2 \\
RS-CS & 19 & 150 & Placed concurrently & - & 2 \\
RS-CSF & 19 & 150 & Placed separately & Exposed & \\
Total & & & & & 2 \\
\hline
\end{tabular}




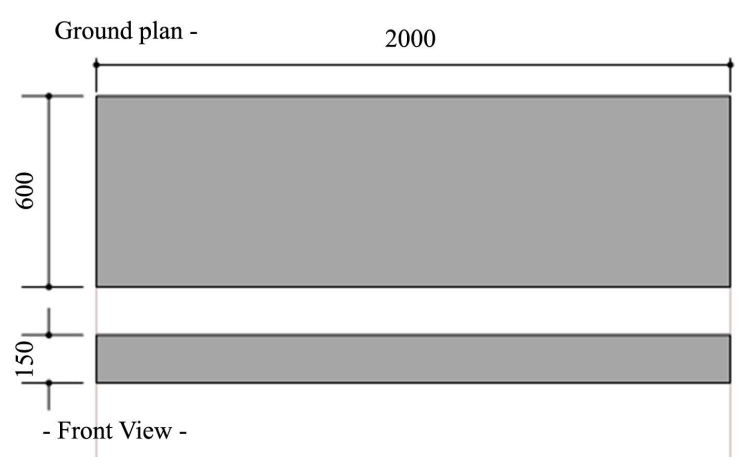

(a)

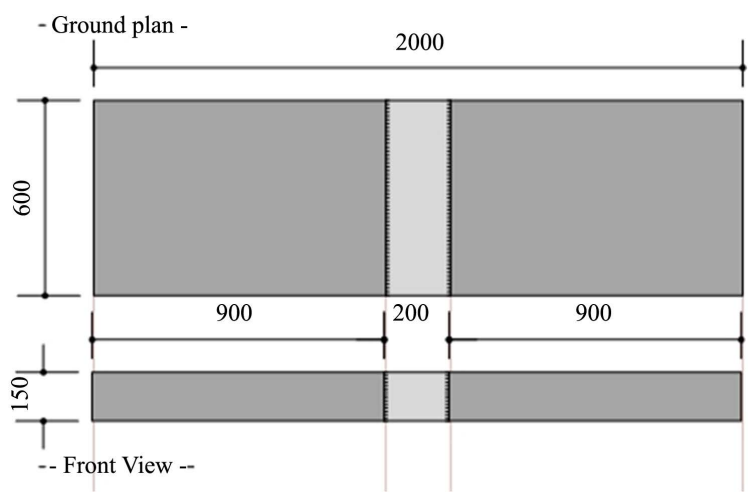

(b)

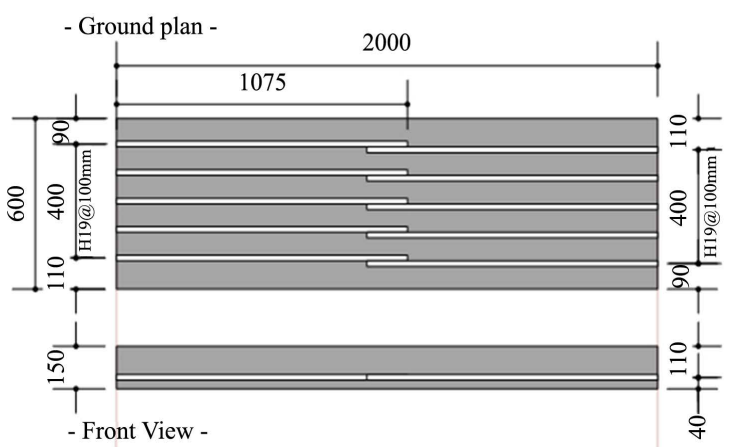

(d)

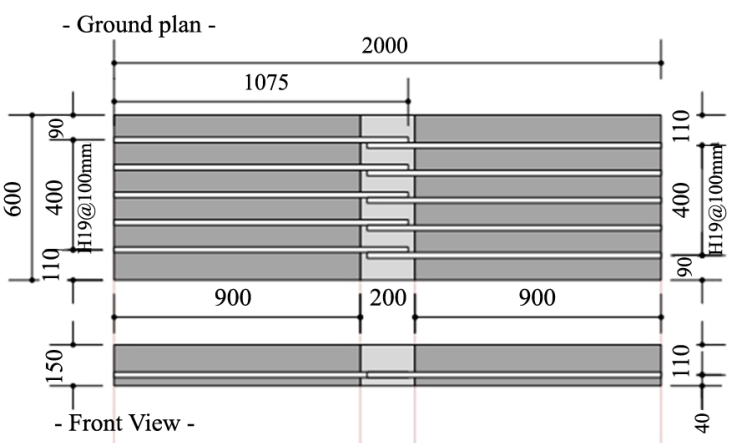

(c)

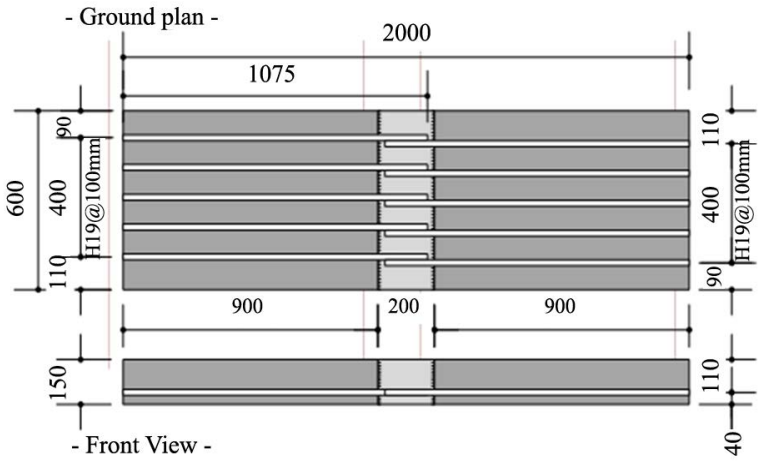

(e)

Figure 1. Dimensions of test members (unit: mm). (a) RN-CU; (b) RN-CSF; (c) RS-CU; (d); RS-CS; (e) RS-CSF.

\subsection{Solution for the Exposure of Steel Fiber}

Curing retardant was used to expose the steel fiber at the interface between the joint and precast deck. The absorption of the curing retardant by the UHPC placed in the joint of the precast deck enabled to delay the strength development in the connection while letting strength develop in other parts. After a definite period, an adequate pressure was applied on the connection to crush concrete placed at the interface. This process is described in Figure 2. The curing retardant was applied uniformly on the interface concrete by means of a sponge on which the agent was sprayed at a rate of $0.002 \mathrm{~g} / \mathrm{mm}^{2}$. A preliminary test was performed to determine the quantity of curing retardant but the results showed that there was practically no difference in the degree of exposure of steel fiber. Accordingly, the curing retardant was simply sprayed to dampen the sponge sufficiently. 24 hours after the first placing, the specimens were stripped off the forms and the steel fibers of the connection were exposed using a high-pressure water jet. This period of 24 hours was also decided through preliminary test. Rust inhibitor was sprayed on the exposed steel fibers to prevent their corrosion prior to the second placing. 


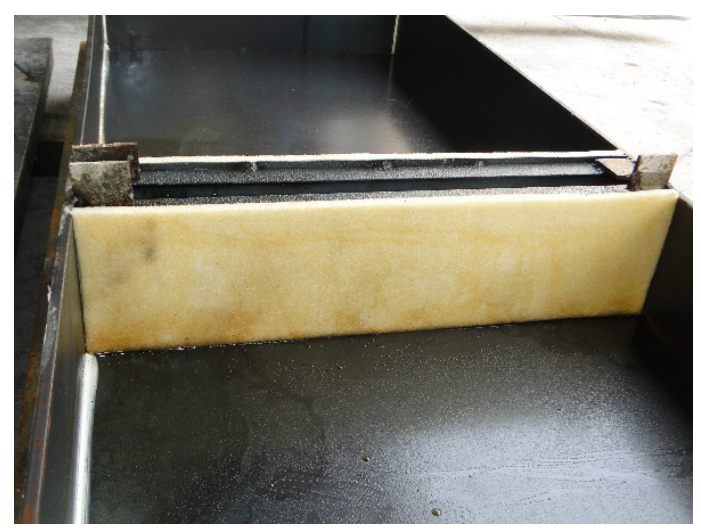

(a)

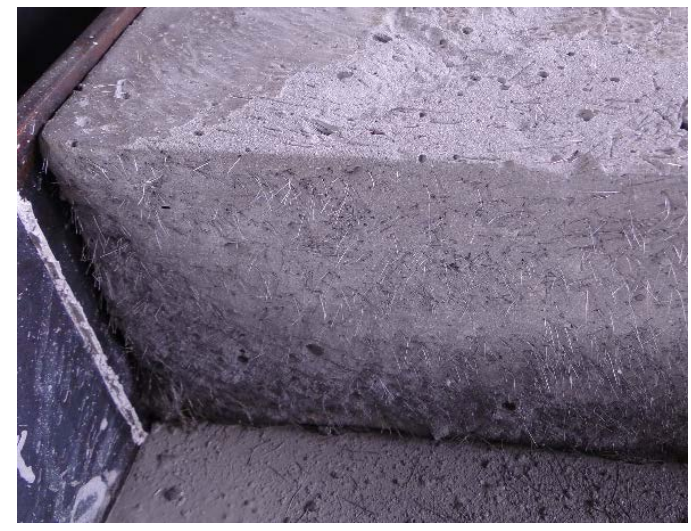

(c)

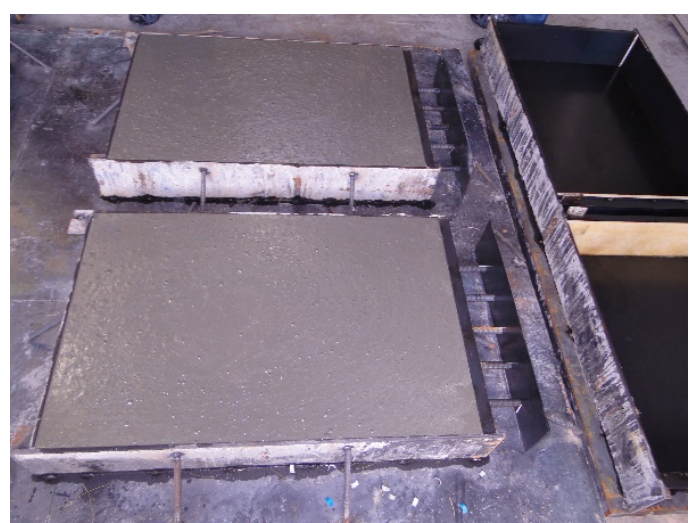

(b)

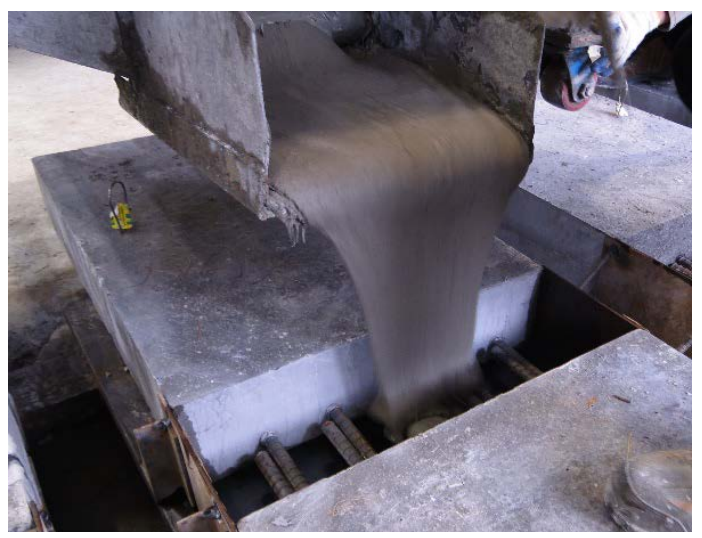

(d)

Figure 2. Process for the steel fiber exposure at the connection interface. (a) Application of curing retardant using a sponge attached to the connection; (b) First placing; (c) Steel fiber exposure by high-pressure water jet after stripping; (d) Second placing.

\subsection{Four-Point Bending Test}

Four-point bending test was carried out to generate the maximum bending moment in the joint section for the identification of the behavior and performance of the joint installed in the transverse positive moment zone. Figure 3 illustrates the loading points and supports of the test member. Loading was applied through displacement control at rate of $0.02 \mathrm{~mm} / \mathrm{s}$ [9]. The deflection, concrete strain and crack width at the connection were measured in real-time during the tests.

As shown in Figure 3, the deflection of the specimen was measured at mid-span and at the loading points but only the deflection at mid-span was used in the analysis. The concrete strain was measured on the lateral faces of the specimen around the interfaces and at mid-span with respect to the height of the specimen. The crack width was measured in both interfaces using crack gages bonded at the positions of the principal cracks of the specimen without joint.

\section{Test Results and Discussions}

\subsection{Strength per Batch}

UHPC was manufactured in 3 batches for the fabrication of the specimens. The first batch was placed for the precast parts of RS-CS and RS-CSF. The second batch was placed for the precast part of RN-CSF. The third batch was used for the specimens RN-CU and RS-CU without joint and placed in the joints of specimens RN-CSF, RS-CS and RS-CSF. Moreover, for quality control purpose, cylinders were manufactured for each batch. Table 2 arranges the averages of the compressive and flexural strengths of the 3 cylinders.

The lower compressive strength observed for the first and second batches in Table 2 can be explained by the 


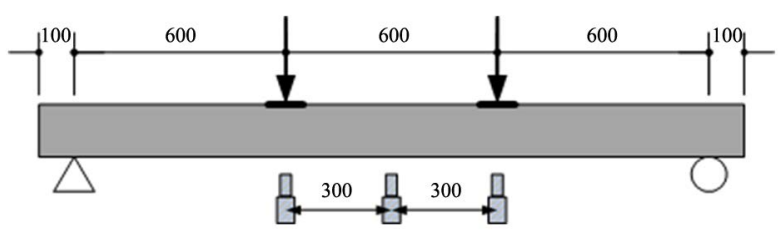

(a)

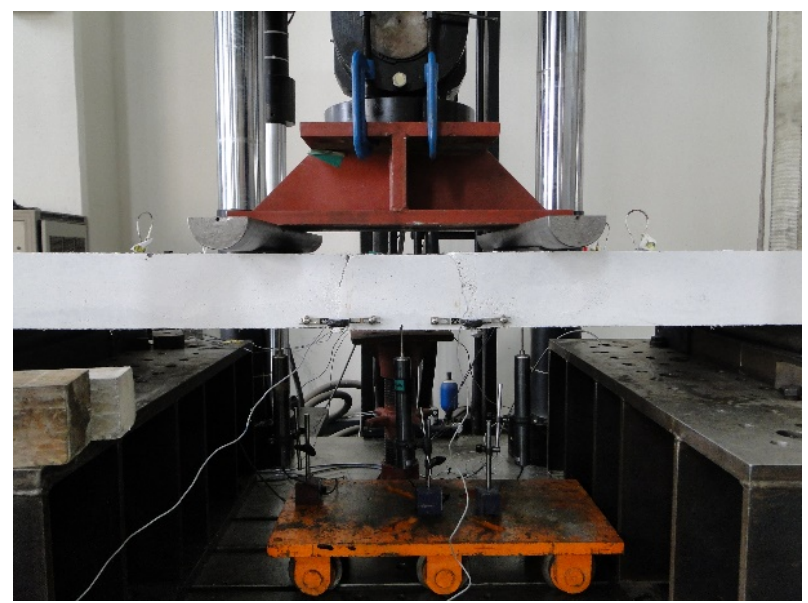

(b)

Figure 3. Four-point bending test. (a) Loading and measuring points (unit: mm); (b) Front view of experiment.

Table 2. Average strengths per batch.

\begin{tabular}{ccc}
\hline & Compressive strength (MPa) & Flexural tensile strength (MPa) \\
\hline Batch 1 & 172.2 & 28.9 \\
Batch 2 & 161.2 & 30.7 \\
Batch 3 & 183.1 & 22.4 \\
Average & 172.2 & 27.3 \\
\hline
\end{tabular}

curing period applied for the batches. The specimen of the third batch was steam-cured during 72 hours whereas the cylinders of the first and second batches were steam-cured during 48 hours. However, the precast parts of the specimens made with the first and second batches were subjected to steam curing for more than 72 hours and could be expected to develop strength higher than the target strength of $180 \mathrm{MPa}$.

The flexural tensile strength of UHPC with compressive strength of $180 \mathrm{MPa}$ runs generally between $35 \mathrm{MPa}$ and $40 \mathrm{MPa}$. The lower flexural tensile strength measured for the third batch is caused by the large number of specimens manufactured using this batch, which required longer time for placing than previewed and resulted in the lower strength of the cylinder manufactured at the end of the fabrication process.

\subsection{Analysis of Load-Deflection Relation at Mid-Span}

The load-deflection curves obtained through static loading test are observed. Figure 4 plots the load-deflection curves measured in each test member. The average ultimate loads are listed in Table 3 for each test member.

For specimen RN-CSF of which connection is realized only by the exposed steel fiber and without lap splice, the ultimate load reaches about $26 \mathrm{kN}$, which can be assumed as an approximate of the flexural resistance provided by the joining force between the exposed steel fiber and concrete. This value corresponds to approximately $10 \%$ of the ultimate load of specimen RN-CU that was placed at once without construction joint. In the case of lap spliced joints, specimens RS-CS and RS-CSF present ultimate loads reduced by about 31\% compared to specimen RS-CU placed at once without joint but exhibit better ductile behavior. The ultimate strength of 


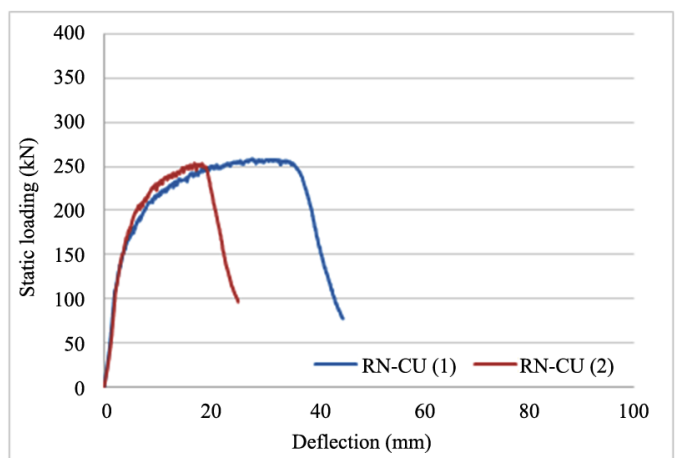

(a)

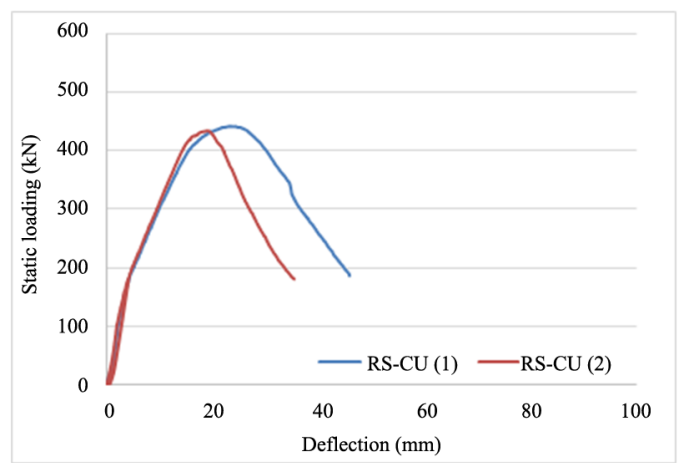

(c)

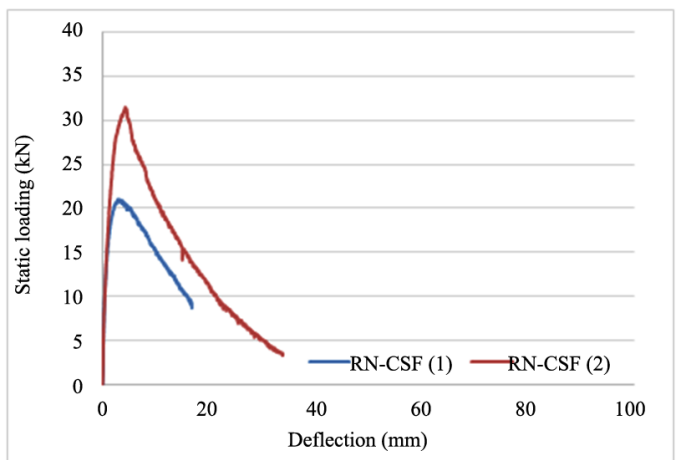

(b)

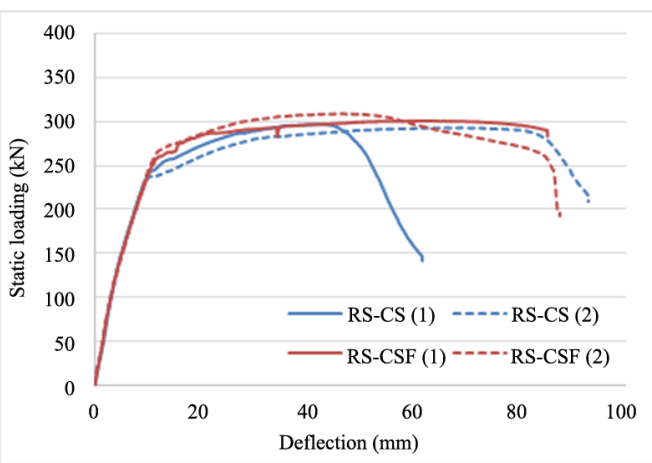

(d)

Figure 4. Load-deflection curves of test members. (a) RN-CU; (b) RN-CSF; (c) RS-CU; (d) RS-CS \& RS-CSF

Table 3. Comparison of average ultimate loads of test members.

\begin{tabular}{cccccc}
\hline Specimen & RN-CU & RN-CSF & RS-CU & RS-CS & RS-CSF \\
\hline Ultimate load $(\mathrm{kN})$ & 256.2 & 26.3 & 438.6 & 295.6 & 305.6 \\
\hline
\end{tabular}

RS-CSF is seen to be larger by about $10 \mathrm{kN}$ than RS-CS. This increment of 3\% indicates that there is practically no effect of the exposure of steel fiber on the ultimate strength. In addition, there is also no change in the stiffness according to the exposure of steel fiber before yielding as shown in Figure 4(d). Accordingly, it can be stated that the exposure of steel fiber does practically not contribute to the increase of the ultimate strength and stiffness.

Besides, specimen RS-CSF with exposed steel fiber secures more stable ductile behavior than specimen RS-CS without exposed steel fiber. The flexural resistance provided by the joining force between the exposed steel fiber and concrete was evaluated to run around $26 \mathrm{kN}$ for RN-CSF and contributed to an increase of $10 \mathrm{kN}$ of the ultimate strength in the case of RS-CSF. On the other hand, the remaining bond force can be seen to contribute to the improvement of the ductile behavior of the specimens. Therefore, the exposure of steel fiber can be exploited as a solution for securing stable ductile behavior of the construction joint.

\subsection{Analysis of Crack Width under Service Load}

Table 4 arranges the change in the crack width under service load according to the exposure of steel fiber. The service load was applied as a concentrated load obtained by converting the moment resulting from the serviceability combination established for a previously designed cable stayed bridge [5] [6]. The so-obtained service load is $96 \mathrm{kN}$. Under application of the service load, the crack widths observed in RS-CS and RS-CSF were respectively $0.18 \mathrm{~mm}$ and $0.15 \mathrm{~mm}$. Both values satisfy the allowable crack width of $0.3 \mathrm{~mm}$ specified in the Concrete Design Code and Commentary [8]. The exposure of steel fiber realized a reduction by about $16.7 \%$ of the crack width under service load. 
Table 4. Change in crack width under service load according to steel fiber exposure.

\begin{tabular}{cccccc}
\hline \multirow{2}{*}{ Specimen } & \multicolumn{2}{c}{ RS-CS } & \multicolumn{3}{c}{ RS-CSF } \\
\cline { 2 - 6 } & Left & Right & Left & Right \\
\hline Crack width $(\mathrm{mm})$ under service load $(96 \mathrm{kN})$ & 0.18 & 0.18 & 0.15 & 0.15 \\
\hline
\end{tabular}

\section{Conclusions}

A method using curing retardant for the exposure of steel fiber at the precast deck-joint interface was proposed in order to improve the serviceability to cracking of the lap spliced UHPC precast deck joint. The change in the flexural performance of the precast deck with construction joint was examined experimentally according to the steel fiber exposure.

For the precast deck with lap spliced joint, it appeared that the steel fiber exposure had poor effect on the increase of the ultimate strength with an increment of $3 \%$ and that the exposure did not have the slightest effect on the stiffness before yielding. This means that the ultimate strength and stiffness of the UHPC precast deck with lap spliced joint depend mostly on the details of the lap splices. However, the steel fiber exposure enabled to secure stable post-yielding ductile behavior of the UHPC precast deck with joint. In addition, it was verified that the crack width in the connection at service load state reduced by about $16.7 \%$.

Even if there are still many features to be improved for the field application of the proposed method using curing retardant for the exposure of steel fiber in the connection of precast deck, this study verified the potential applicability of the method for securing stable ductile behavior and reducing the crack width at the connection interface of UHPC precast deck segments.

\section{Acknowledgements}

This research was supported by a grant (13SCIPA02) from Smart Civil Infrastructure Research Program funded by Ministry of Land, Infrastructure and Transport (MOLIT) of Korea government and Korea Agency for Infrastructure Technology Advancement (KAIA).

\section{References}

[1] Graybeal, B.A. (2008) UHPC in the US Highway Transportation System. 2nd International Symposium on Ultra High Performance Concrete, Kassel, 11-17.

[2] Resplendino, J. (2008) Ultra-High Performance Concretes-Recent Realizations and Research Programs on UHPFRC Bridges in France. 2nd International Symposium on Ultra High Performance Concrete, Kassel, 31-43.

[3] Graybeal, B.A. and Swenty, M. (2012) UHPFRC for Prefabricated Bridge Component Connections. 3rd International Symposium on UHPC and Nanotechnology for High Performance Construction Materials, Kassel, 663-668.

[4] Hwang, H.H., Yoo, D.M., Park, S.Y. and Kim, B.S. (2009) Optimized Design of UHPC Bridge Deck Slab for Hybrid Cable-Stayed Girder Bridge. Proceeding of 13th REAAA Conference, Incheon, 1-12.

[5] Korea Institute of Civil Engineering and Building Technology (2012) Development of Deck Systems for Hybrid CableStayed Bridge. KICT 2012-080, Goyang.

[6] Hwang, H.H., Yeo, I.S., Cho, K.H. and Park, S.Y. (2011) Evaluation of Flexural Strength for UHPC Deck Joints with Lap-Spliced Reinforced Steel Bar. Journal of Korea Institute for Structural Maintenance and Inspection, 15, 92-99. (In Korean) http://dx.doi.org/10.11112/jksmi.2011.15.6.092

[7] Korea Road \& Transportation Association (2010) Korean Highway Bridge Design Code. Korea Road \& Transportation Association, Seoul.

[8] Korea Concrete Institute (2007) Concrete Design Code and Commentary. Korea Concrete Institute, Seoul.

[9] Kang, S.T., Park, J.J., Koh, G.T. and Kim, S.W. (2008) Evaluation on Flexural Capacity of Reinforced Concrete Beams with Ultra-High Performance Cementitious Composites. Journal of Korea Institute for Structural Maintenance and Inspection, 12, 81-90. (In Korean) 
Scientific Research Publishing (SCIRP) is one of the largest Open Access journal publishers. It is currently publishing more than 200 open access, online, peer-reviewed journals covering a wide range of academic disciplines. SCIRP serves the worldwide academic communities and contributes to the progress and application of science with its publication.

Other selected journals from SCIRP are listed as below. Submit your manuscript to us via either submit@scirp.org or Online Submission Portal.
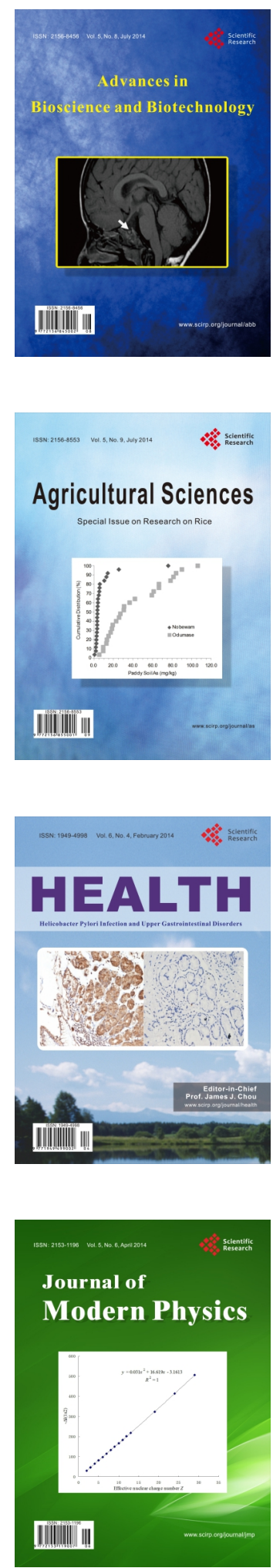
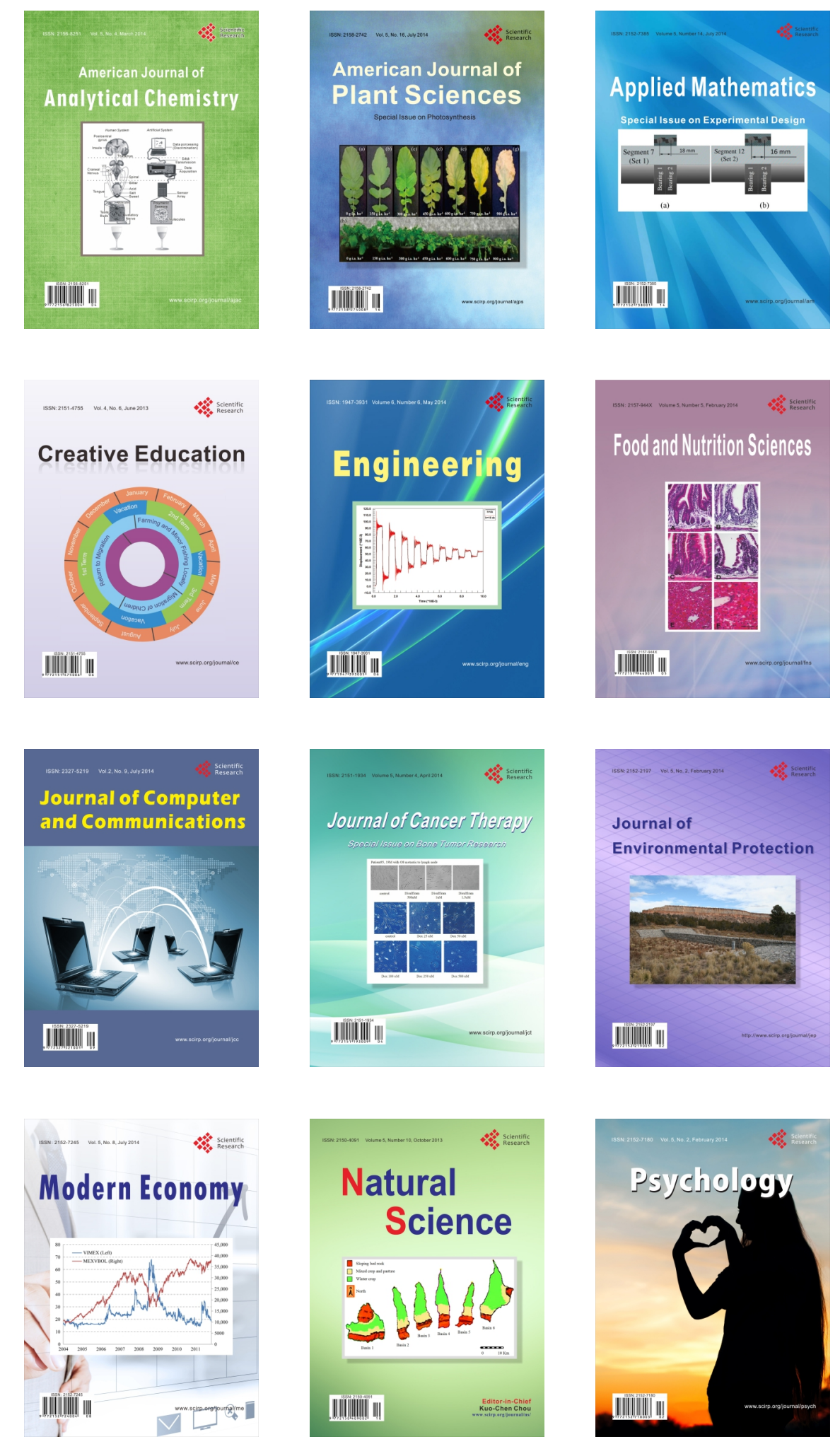